\title{
EFICÁCIA DO HERBICIDA GLYPHOSATE NO CONTROLE DE Brachiaria decumbens NA CULTURA DA GUARIROBA (Syagrus oleracea)
}

\author{
Joaquim A. Carvalho ${ }^{1}$, Marcos Rodrigues Vieira ${ }^{2}$, Vera L. M. Santos ${ }^{1}$ e Carlos M. Santos ${ }^{1}$ \\ ${ }^{1}$ Universidade Federal de Uberlândia - UFU, Instituto de Ciências Agrárias - ICIAG, Uberlândia, MG. \\ ${ }^{2}$ Discente do Curso de Agronomia. UFU / ICIAG, Uberlândia, MG.
}

\begin{abstract}
RESUMO
Este trabalho foi realizado com objetivo de avaliar o efeito, em área total, de diferentes doses de glyphosate sobre a cultura da guariroba e no controle de Brachiaria decumbens em pós-emergência. Foram utilizadas as doses de 972, 1215, 1458, $1701 \mathrm{e} 1944 \mathrm{~g} / \mathrm{ha}$. O delineamento experimental foi o de blocos casualizados, com quatro repetições. O volume de calda aplicado foi de $200 \mathrm{~L} / \mathrm{ha}$, sob temperatura de $26^{\circ} \mathrm{C}$ e umidade relativa de $84 \%$, utilizando-se pulverizador manual, pressurizado por $\mathrm{CO}_{2}$ a $2,2 \mathrm{kgf} / \mathrm{cm}^{2}$, com seis bicos tipo leque de jato plano TT 110.02. Avaliou-se a fitotoxicidade e o controle de B. decumbens aos 6 , 12, 21 e 31 dias após a aplicação (DAA). Concluiu-se que a espécie Syagrus oleracea é altamente tolerante ao herbicida glyphosate, mesmo na dose de $1944 \mathrm{~g} / \mathrm{ha}$. Independentemente da dose estudada, o glyphosate foi muito eficaz no controle de plantas jovens de Brachiaria decumbens, uma vez que exerceu um controle de $100 \%$.
\end{abstract}

Palavras-chave: capim-braquiária, herbicida, palmeira, planta daninha.

\begin{abstract}
The efficiency of glyphosate in the control of Brachiaria decumbens in guariroba crop (Syagrus oleracea)

This study was carried out to analyze the use, in total area, of different doses of glyphosate in guariroba crop to control Brachiaria decumbens in post-emergence. The commercial product Roundup Transorb (648 g of glyphosate / L) was applied at the doses of : 972, 1215,1458, 1701 and $1944 \mathrm{~g} / \mathrm{ha}$. The experimental design was a random blocks, with four repetitions. The volume of solution applied was $200 / \mathrm{L} / \mathrm{ha}$, at a temperature of $26^{\circ} \mathrm{C}$ and relative humidity of $84 \%$, by the use of a manual sprayer, pressured by $\mathrm{CO}_{2}$ at $32 \mathrm{lb} / \mathrm{in}^{2}$, with six flat nozzles TT 110.02 . Phytotoxicity and the control of Brachiaria decumbens were analyzed 6, 12, 21 and 31 days after chemical application (DAA). It was conclued that the species Syagrus oleracea was highly tolerant to the herbicide glyphosate, even at the highest studied dose and the herbicide glyphosate independently of the studied dose, was very efficient in the control of young Brachiaria decumbens plants, exerting $100 \%$ control.
\end{abstract}

Key words: herbicide, palm tree, weed. 
Joaquim A. Carvalho et al.

\section{INTRODUÇÃO}

A espécie Syagrus oleracea, pertencente á família Palmaceae, morfologicamente caracteriza-se por um caule de 10 a $20 \mathrm{~m}$ de altura e 20 a $30 \mathrm{~cm}$ de diâmetro, de 15 a 20 folhas de 2 a $3 \mathrm{~m}$ de comprimento, dispostas em espiral e levemente arqueadas, 100 a 150 folíolos em grupos de 2 a 5, dispostos em planos diferentes e frutos verde-amarelados (Lorenzi, 1996).

Há no Brasil, dentro da família Palmaceae, cerca de 17 gêneros de palmeiras reconhecidamente apropriadas para a produção de palmito destinado à alimentação humana. Dessa forma, tem-se buscado o aproveitamento dessas espécies com comprovado potencial de utilização comercial (Bonnas \& Jordão, 1996).

A importância da guariroba (Syagrus oleracea) está ligada à construção civil, produção de mel, ornamentação, alimentação animal e, principalmente, à alimentação humana, na forma de palmito. Segundo Lorenzi (1992), o caule é empregado para estacas, moirões, ripas e calhas para água. A polpa do fruto é comestível e muito apreciada pelos bovinos e suínos. A amêndoa é comestível, sendo comercializada em feiras nos estados do nordeste. As folhas são usadas para confecção de vassouras e as flores são melíferas. A palmeira é ornamental, sendo uma das mais cultivadas para arborização urbana nas cidades do Brasil Central. É ótima para plantios mistos em áreas de preservação permanente.

O sistema de produção da guariroba apresenta relação custo/beneficio muito elevada, quando comparada com os sistemas de produção de laranja, milho e arroz, sendo altamente lucrativa, apresentando alto retorno do capital investido (Aguiar et al., 1996). Há uma tendência de crescimento do mercado para este produto, principalmente se ocorrer a implementação de sua industrialização. Porém, há limitação à expansão da produção, por falta de estudos sobre a domesticação da planta e o cultivo comercial.

Uma das limitações para o cultivo comercial da guariroba é a falta de informações técnicas, pois praticamente inexistem resultados de pesquisas com esta cultura, permanecendo várias indagações com relação aos espaçamentos utilizados, populações de plantas, adubação, produção de mudas, controle fitossanitário, controle de plantas daninhas, variedades, uniformidade e qualidade do palmito. Atualmente, todas as informações a respeito da cultura são dadas por produtores que, muitas vezes, por tentativa, vem procurando melhorar a produtividade e reduzir a idade de corte do palmito (Nascente \& Peixoto, 1999).

No processo produtivo da guariroba existem vários tratos culturais indispensáveis para um bom desenvolvimento da cultura, como o controle de plantas daninhas, adubações, capação de folhas, controle de pragas e doenças, entre outros. O controle de plantas daninhas é um fator que exige grande atenção devido ao fato da cultura possuir um desenvolvimento lento, principalmente nos dois primeiros anos, o que possibilita alta infestação e competição das espécies daninhas, dificultando seu cultivo e onerando dessa forma o custo de produção, tendo em vista que geralmente, o controle é feito por meio de capinas manuais.

A presença de plantas daninhas pode causar séria concorrência em água, luz e nutrientes à guariroba (Diniz \& Sá, 1995). O controle precisa ser preciso e oportuno, iniciandose por meio de um bom preparo do solo, devendo dar continuidade à medida que a cultura for desenvolvendo, por meio de capinas manuais ou com a utilização de roçadeiras, para eliminar a competição das plantas daninhas, especialmente gramíneas (Palmito..., 1998).

Existem vários métodos para controlar as plantas daninhas, dentre eles o controle químico, que não é muito utilizado na cultura da guariroba, principalmente devido à falta de conhecimento de herbicidas que possam ser utilizados sem que haja comprometimento das plantas cultivadas. Os herbicidas a base de glyphosate apresentam um grande potencial de utilização na cultura da guariroba.

Este trabalho teve como objetivo estudar diferentes doses do herbicida glyphosate no controle de Brachiaria decumbens, em pós-emergência, na cultura da guariroba.

\section{MATERIAL E MÉTODOS}

O experimento foi conduzido em área experimental na Fazenda Capim Branco, da Universidade Federal de Uberlândia, com altitude de 920 metros, latitude de $18^{\circ} 54^{\prime} 40^{\prime \prime}$ S e longitude de 48 13 '04"'W, situada no município de Uberlândia/MG, no período de dezembro de 1998 à janeiro de 2000.

Foram avaliadas, além da testemunha, cinco doses do herbicida glyphosate (produto comercial Roundup Transorb, na concentração de $648 \mathrm{~g} / \mathrm{l}$ de glyphosate): 972, 1215, 1458, 1701 e $1944 \mathrm{~g} / \mathrm{ha}$. O delineamento utilizado foi o de blocos casualizados, com quatro repetições. As parcelas foram compostas de quatro linhas de cinco metros de comprimento, espaçadas de 75 centímetros.

As sementes de guariroba foram coletadas no chão, após a queda, e secadas ao sol durante três a cinco dias. O tempo entre a coleta e a semeadura foi de uma a duas semanas. As sementes utilizadas não foram despolpadas, com exceção daquelas que ao serem coletadas, já haviam sido despolpadas por animais.

A semeadura foi realizada em $22 / 12 / 1998$, distribuindose, inicialmente, as sementes sobre o solo preparado com uma aração e duas gradagens, num espaçamento de $75 \mathrm{~cm}$ entre fileiras e de 35 a $40 \mathrm{~cm}$ entre sementes. A seguir, as sementes foram enterradas, à profundidade de aproximadamente três centímetros, com auxilio de um soquete de madeira.

Como o período de germinação da guariroba é relativamente longo, foi efetuado o controle das plantas daninhas, até que a emergência iniciasse, com duas aplicações de glyphosate, em área total. A primeira foi realizada aos 32 
dias após a semeadura, utilizando-se 3,3 L/ha do produto comercial. A segunda aplicação foi feita aos 72 dias após a semeadura, utilizando-se 4,4 L/ha. Após a segunda aplicação fez-se um arranquio manual de algumas plantas daninhas que persistiram, da espécie Ipomoea grandifolia. As espécies encontradas na área experimental foram Acanthospermum australe (carrapichinho), Alternanthera tenella (apaga-fogo), Mimosa pudica (malícia), Ipomoea grandifolia (corda-deviola) e Panicum maximum (capim-colonião).

A emergência da guariroba iniciou aos 75 dias após a semeadura (DAS), sendo que aos 210 dias esta se estabilizou e aos 350 dias correspondeu a $37,1 \%$ das sementes semeadas, obtendo-se um estande de 13389 plantas/ha. Foram feitas duas adubações, sendo a primeira aos $250 \mathrm{DAS}$, em um pequeno sulco lateral às linhas, utilizando-se 55, 222 e 50 kg/ha de uréia, superfosfato simples e cloreto de potássio, respectivamente. A segunda adubação, com $140 \mathrm{~kg} /$ ha de sulfato de amônia, foi realizada aos $280 \mathrm{DAS}$, aplicados na superfície próximo às linhas.

A semeadura da Brachiaria decumbens foi realizada em sulcos, nas entrelinhas da cultura da guariroba, quando seu estande estava definido, aos 320 DAS. Semeou-se manualmente, $27,5 \mathrm{~kg}$ / ha de sementes com $80 \%$ de germinação e valor cultural de $32,5 \%$, em sulcos de aproximadamente dois centímetros de profundidade. A emergência, iniciou-se sete dias após a semeadura.

A aplicação dos tratamentos foi realizada aos 354 dias após a semeadura da guariroba e aos 26 dias após a emergência das plantas de $B$. decumbens, em 11/12/1999. O volume de calda aplicado foi de $200 \mathrm{~L} / \mathrm{ha}$, sob temperatura de $26^{\circ} \mathrm{C}$ e umidade relativa do ar de $84 \%$, utilizando-se um pulverizador manual, pressurizado por $\mathrm{CO}_{2}$ a $2,2 \mathrm{kgf} / \mathrm{cm}^{2}$, com seis bicos tipo leque, jato plano TT 110.02. A aplicação foi realizada no período da manhã, das $9 \mathrm{~h}$ às $9 \mathrm{~h} 30$, sem ocorrência de chuva durante o período de absorção do produto.

Por ocasião da aplicação dos tratamentos, as plantas de guariroba encontravam-se, em sua maioria, com duas folhas abertas e iniciando a abertura da terceira. As plantas de
BRADC, na maioria, apresentavam quatro a seis folhas, com 1 a 3 perfilhos e altura variável de 8 a $18 \mathrm{~cm}$, com uma população de 70 plantas por metro quadrado.

O controle das plantas daninhas foi avaliado visualmente aos 6, 12, 21 e 31 dias após a aplicação dos tratamentos (DAT), adotando-se a escala percentual de notas, sendo zero correspondente a nenhum controle e 100 equivalente a controle total das plantas de $B$. decumbens. Nas avaliações de fitotoxicidade, também realizada aos $6,12,21$ e 31 DAT, sobre as plantas de guariroba, foi utilizada a escala da EWRC (Australian Weeds Committee, 1979).

Foram realizadas as análises de variância e as médias foram comparadas pelo teste de Duncan, a 5\% de significância.

\section{RESULTADOS E DISCUSSÃO}

Em todas as doses estudadas, o glyphosate foi eficaz no controle de Brachiaria decumbens. A percentagem de controle aos 6 DAT, nas doses de 1215, 1458, 1701 e 1944 g/ha, foram de 97,5, 98,3, 98,0 e 98,0\%, respectivamente, não diferindo entre si pelo teste de Duncan a $5 \%$ de probabilidade. A menor dose diferiu das demais, porém com controle de $96 \%$. Nas avaliações realizadas aos 12, 21 e 31 DAT, o controle de Brachiaria decumbens foi total, independentemente da dose avaliada (Tabela 1).

A alta eficácia do produto sobre a espécie já era esperada, mesmo nas menores doses, uma vez que é recomendada a dose de 2592 g/ha para esta espécie, com plantas já perenizadas . As plantas de Brachiaria decumbens, ainda jovens, são mais susceptíveis ao produto do que as adultas ou perenizadas como as de pastagens. Esta maior susceptibilidade das plantas jovens é devida ao fato de estarem em crescimento, estando assim com seu metabolismo pleno, com boas relação entre área foliar e radicular, menor barreira à absorção e maior ativação à translocação do herbicida para suas organelas de atuação. Esta interação positiva entre planta e produto, para atuação do herbicida, provavelmente foi

Tabela 1. Controle de Brachiaria decumbens na cultura da guariroba. Fazenda Experimental Capim Branco, Uberlândia, MG. 2000.

\begin{tabular}{|c|c|c|c|c|c|}
\hline \multirow[b]{3}{*}{ Nome comum } & \multirow[t]{2}{*}{ Tratamento } & \multicolumn{3}{|c|}{ Controle (\%) } & \multirow[b]{3}{*}{31} \\
\hline & & & & & \\
\hline & Dose (g/ha) & 6 & 12 & 21 & \\
\hline Testemunha & - & $0,0 \mathrm{c}^{1}$ & 0 & 0 & 0 \\
\hline Glyphosate & 972 & $96,0 \mathrm{~b}$ & 100 & 100 & 100 \\
\hline Glyphosate & 1215 & $97,5 \mathrm{a}$ & 100 & 100 & 100 \\
\hline Glyphosate & 1458 & $98,3 \mathrm{a}$ & 100 & 100 & 100 \\
\hline Glyphosate & 1701 & $98,0 \mathrm{a}$ & 100 & 100 & 100 \\
\hline Glyphosate & 1944 & $98,0 \mathrm{a}$ & 100 & 100 & 100 \\
\hline $\mathrm{CV}(\%)$ & & 0,8 & - & - & - \\
\hline
\end{tabular}

${ }^{1} \mathrm{Na}$ coluna, as médias seguidas pela mesma letra, não diferem significativamente, a 5\% de probabilidade, pelo teste de Duncan. 
favorecida pelas excelentes condições do meio, durante a aplicação dos tratamentos. Justificando, inclusive, o alto controle da espécie, aos 12 DAT, mesmo na menor dose avaliada.

Em função da expansão da área plantada com esta cultura, conforme cita Abreu apud Nascente \& Peixoto (1999), serem predominantemente oriundas de pastagens degradadas e com presença de $B$. decumbens, estudos dessa natureza, tornam-se importantes, já que as plantas, quando perenizadas, em estádio de desenvolvimento mais avançado ou mesmo quando jovens, porém com baixo metabolismo, necessitarão de maior dose do produto.

De acordo com a escala da EWRC, o glyphosate causou um sintoma de fitotoxicidade muito leve (2), independentemente das doses utilizadas, sendo verificado, principalmente, nas plantas cujas pontas das folhas estavam em contato com o solo. Entretanto, não houve comprometimento no desenvolvimento das plantas, como pode ser observado nas avaliações posteriores (12, 21 e 31 DAT), quando os sintomas desapareceram (Tabela 2). Estes resultados mostram que o produto não prejudicou o desenvolvimento das plantas mesmo quando se utilizou a maior dose, o que pode representar uma boa alternativa de manejo para o produtor, em função da diversidade de espécies que normalmente infestam a cultura. Essa seletividade do herbicida para a espécie estudada mostra-se importante, uma vez que o produto não é seletivo para maioria das palmeiras que se desenvolvem no Brasil.

Há necessidade de estudos complementares sobre o assunto, envolvendo todo o ciclo da cultura, para verificar a possibilidade de interferência do produto na produção de palmito.

Tabela 2. Fitotoxicidade, de acordo com a tabela da EWRC, aos 6, 12, 21 e 31 dias após a aplicação dos tratamentos (DAT). Fazenda Experimental Capim Branco, Uberlândia, MG. 2000.

\begin{tabular}{lccccc}
\hline \multicolumn{2}{c}{ Tratamento } & \multicolumn{4}{c}{ Fitotoxicidade } \\
\hline Nome & Dose & \multicolumn{4}{c}{ DAT } \\
\cline { 2 - 6 } comum & (g/ha) & $\mathbf{6}$ & $\mathbf{1 2}$ & $\mathbf{2 1}$ & $\mathbf{3 1}$ \\
\hline Testemunha & - & 1 & 1 & 1 & 1 \\
Glyphosate & 972 & 2 & 1 & 1 & 1 \\
Glyphosate & 1215 & 2 & 1 & 1 & 1 \\
Glyphosate & 1458 & 2 & 1 & 1 & 1 \\
Glyphosate & 1701 & 2 & 1 & 1 & 1 \\
Glyphosate & 1944 & 2 & 1 & 1 & 1 \\
\hline
\end{tabular}

\section{CONCLUSÕES}

A espécie Syagrus oleracea é altamente tolerante ao herbicida glyphosate, mesmo na dose de $1944 \mathrm{~g} / \mathrm{ha}$.

O glyphosate, nas doses de 972, 1215, 1458, $1701 \mathrm{e}$ 1944 g/ha, é muito eficaz no controle de plantas jovens de Brachiaria decumbens.

\section{LITERATURA CITADA}

AGUIAR, J.L.P.; ALMEIDA, S.P.; PEREIRA, G. Avaliação econômica de um sistema de produção de gueroba (Syagrus oleracea Becc.) em Argoiânia, GO. In: SIMPÓSIO INTERNACIONAL SOBREECOSSISTEMAS FLORESTAIS, 4. Belo Horizonte, MG, 1996. Resumos... Belo Horizonte: BIOSFERA, 1996. p.333-334.

AUSTRALIAN WEEDS COMMITTEE. Guidelines for field evaluation of herbicides. Canberra Australian Government Publishing Service, 1979. P. A1-5.

BONNAS, D.S.; JORDÃO, P. R. Aspectos físico-químicos da guariroba (Syagrus oleracea Becc.) e sua utilização para fabricação de palmito em conserva. In: SIMPÓSIO INTERNACIONAL SOBRE ECOSSISTEMAS FLORESTAIS, 4. Belo Horizonte, MG, 1996. Resumos... Belo Horizonte: BIOSFERA, 1996. 293-294.

DINIZ, J.A; SÁ, L. F. A cultura da guariroba. Goiânia: EMATER - GO, 1995. 16 p. (Boletim Técnico, 3).

LORENZI, H. Árvores brasileiras: manual de identificação e cultivo de plantas arbóreas nativas do Brasil. Nova Odessa: Plantarum, 1992.352p.

LORENZI, H. Palmeiras no Brasil: nativas e exóticas. Nova Odessa: Plantarum, 1996.303p.

NASCENTE, A.S.; PEIXOTO, N. Peso de sementes e emergência de plântulas de guariroba (Syagrus oleracea) no Estado de Goiás. Goiânia: EMATER - GO, 1999. 10 p.

PALMITO GUARIROBA (Syagrus oleracea (Mart.) Becc.).[online]. Agro-Fauna Com. de Insumos, 1998. P. 12. Web:Http://www.agrofauna.com/palmito guariroba.htm. 